\title{
Gravidez na adolescência:
}

\section{um estudo exploratório sobre o início da experiência da gravidez}

Teenage pregnancy: an exploratory study of the beginning of the pregnancy experience

Na sociedade atual as mudanças têm ocorrido em ritmo acelerado. As sociedades urbanas, em geral, tornaram-se cada vez mais complexas, exigindo maior qualificação escolar e profissional dos jovens para inserção no mercado de trabalho e, conseqüentemente, na vida adulta. Desta forma, a gravidez na adolescência, que vem aumentando no Brasil e no mundo, é motivo de preocupação por representar um paradoxo dentro das exigências da sociedade atual.

O objetivo deste trabalho foi observar o início da experiência de gravidez na vida emocional da adolescente, considerando a influência do seu contexto familiar e social nessa experiência. Recortou-se o momento inicial da gravidez para ser possível observar a forma como a adolescente se reorganiza emocionalmente diante do impacto do diagnóstico, pois este fenômeno vai traduzir o lugar e a função que a gravidez tem para ela dentro de sua família.

O grupo investigado foi constituído por 16 adolescentes grávidas com idade variando entre 14 e 19 anos. O tamanho do grupo foi definido conforme critério de saturação, sugerido por Patton (1990). Para coleta dos dados foram utilizados dois instrumentos: entrevista aberta, conforme proposto por Bleger (1975), e questionário sócioeconômico, conforme proposto por Rodrigues (1978). Este material foi submetido à análise de conteúdo, conforme proposto por Bardin (1977). Desta análise qualitativa extraíram-se categorias de análise para interpretação dos resultados conforme referencial teórico adotado, envolvendo a Psicanálise de orientação inglesa e a teoria sociológica de Pierre Bourdieu.
A análise dos dados levantados indica que as jovens com dificuldades de se posicionarem no mundo por meio da escola e colocação profissional engravidam como tentativa de dar início a um processo de (re)construção de identidade. Essas adolescentes com histórias de deficiências afetivas mostraram falhas no seu processo de formação de identidade que vieram a ser denunciadas no momento de transição para a vida adulta. Assim, a gravidez pode ser compreendida como um 'estado de moratória diante do sentimento de dívida' apresentado por essas adolescentes no seu processo de desenvolvimento pessoal. Com a gravidez ganham tempo para dar início a um processo de (re)definição de identidade, buscando uma forma de se posicionarem no mundo. Importante ressaltar que esta é mais uma tentativa, que pode dar certo ou não no decorrer da gestação e maternidade.

Resultados obtidos poderão ser considerados em propostas de ações de prevenção a gravidez precoce em ambulatórios e hospitais, dentro de programas de educação em saúde, enfatizando as questões relacionadas à formação de identidade dos adolescentes em conjunto com as informações sobre métodos contraceptivos.

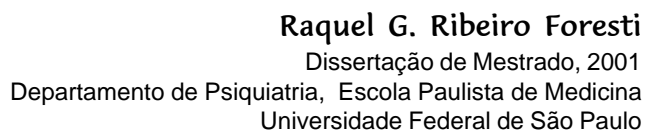

PALAVRAS-CHAVE: gravidez; adolescência. KEYWORDS: pregnancy; adolescence. PALABRAS CLAVE: embarazo; adolescencia.

Recebido para publicação em: 04/07/01. Aprovado para publicação em: 19/07/01. 